\title{
Um Guia Indispensável para os que Trabalham com Irradiação de Micro-ondas Aplicada a Síntese Orgânica
}

\author{
por Rodrigo O. M. A. de Souza
}

editora Wiley-VCH publicou, no primeiro semestre de 2009 , mais um título dedicado à tecnologia de irradiação de micro-ondas, denominado "Pratical Microwave Synthesis for Organic Chemists", escrito pelos Professores C. Oliver Kappe da Karl-Franzens Universität Graz (Áustria), S. Shaun Murphree do Allegheny College (EUA) e pela Dra. Doris Dallinger também da KarlFranzens Universität Graz. Este é o segundo livro dedicado à irradiação de micro-ondas, publicado pelo Prof. C. Oliver Kappe, que em 2006, lançou o livro "Microwaves in Organic and Medicinal Chemistry" em co-autoria com o Dr. A. Stadler.

O livro "Pratical Microwave Synthesis for Organic Chemists" em suas 299 páginas tem como principal objetivo servir de guia a químicos orgânicos que estão se iniciando na utilização de equipamentos dedicados a irradiação de micro-ondas. O livro descreve nos dois primeiros capítulos um histórico da evolução da irradiação de micro-ondas aplicada à síntese orgânica, seguido por noções gerais da teoria do processo de irradiação de micro-ondas. Os dois primeiros capítulos fornecem ao leitor o embasamento necessário ao completo entendimento do restante do livro. É feita uma discussão crítica sobre a existência de "efeitos de micro-ondas" ou de "efeitos térmicos", onde diversos artigos da literatura são analisados e discutidos sob uma ótica imparcial, apesar de o autor ser um dos defensores dos efeitos térmicos.

A seção denominada "Equipment Review" tem como objetivo fornecer ao leitor informações sobre os equipamentos disponíveis no mercado, mostrando as características de cada um, de modo a permitir a escolha adequada de um equipamento. Tabelas comparativas também são fornecidas, indicando os prós e contras de diferentes equipamentos e configurações.

O aspecto mais interessante do livro está no capítulo 6, em que estão relacionados protocolos experimentais para diversas reações orgânicas, entre as quais se pode destacar: a condensação de Knoevenagel e as reações de Grignard, Diels-Alder, Biginelli, Suzuki, entre outras. Nestes protocolos experimentais são fornecidos detalhes sobre os procedimentos que devem ser adotados, indicando qual foi 0 equipamento utilizado, temperatura, tempo de reação, razão molar entre os reagentes (o CAS de todos os reagentes é fornecido), procedimentos para isolamento, rendimentos obtidos, dados espectroscópicos e gráficos relacionando temperatura, pressão e tempo de reação, obtidos através do software do equipamento de microondas. Estas informações facilitam a
Data de publicação na Web: 21 de Dezembro de 2010
Recebido em 23 de Setembro de 2009
Aceito para publicação em 20 de Dezembro de 2010

reprodução dos resultados, servindo como uma boa estratégia de familiarização do usuário com o equipamento.

O livro "Pratical Microwave Synthesis for Organic Chemists" é um guia indispensável para todos aqueles que trabalham com irradiação de micro-ondas aplicada à síntese orgânica, principalmente para os iniciantes no uso da técnica, e uma fonte permanente de consulta para os pesquisadores mais experientes, devido à riqueza de informações contidas no texto.

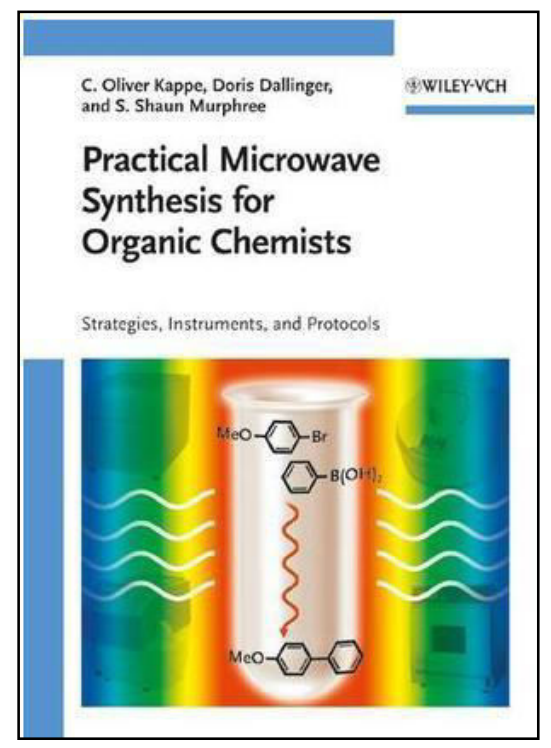

\footnotetext{
* Universidade Federal do Rio de Janeiro, Instituto de Química, Departamento de Química Orgânica, CT, Bloco A, Laboratório 641, Cidade Universitária, 21949-900, Rio de Janeiro-RJ, Brasil.

Mrodrigosouza@iq.ufri.br 